\title{
EFEITOS DE MÉTODOS DE ESCARIFICAÇÃO NA GERMINAÇÃO DE SEMENTES DE CINCO LEGUMINOSAS FORRAGEIRAS $\left({ }^{1}\right)$
}

Luiz D'Artagnan de Almeida (2), Seção de Leguminosas, Jocely A. Maeda, Seção de Sementes, e SôniA M. P. FAlivene, Seção de Leguminosas, Instituto Agronômico

\section{SINOPSE}

Cinco espécies de leguminosas forrageiras, soja-perene (Glycine wightii), siratro (Macroptilium atropurpureum), centrosema (Centrosema pubescens), calopogônio (Calopogonio mucunoides) e cudzu-tropical (Pueraria phaseoloides), foram estudadas quanto ao poder germinativo das sementes, avaliando-se a necessidade de escarificação logo após a colheita e durante o periodo do armazenamento, através da utilização de ácido sulfúrico concentrado, calor, atrito entre lixas e água quente. Verificou-se ainda a possibilidade de haver uma relação entre coloração do tegumento e porcentagem de sementes duras.

Quando não escarificadas, as sementes das cinco espécies apresentaram alta porcentagem de sementes duras, e o repouso não possibilitou a melhoria na germinação, com exceçăo da centrosema.

Todos os métodos de escarificação melhoraram o índice de germinação das sementes, sobressaindo o ácido sulfúrico como o mais eficiente para todas as espécies. O efeito do calor foi bem melhor para cudzu-tropical e, o atrito entre lixas, foi apenas razoável para todas as espécies. A água quente proporcionou bons indices de germinaçâo para siratro e calopogônio, provocando, entretanto, a ocorrência de alta porcentagem de sementes mortas no final do periodo de armazenamento. Para longos períodos de armaz nnamento, é preferível, em qualquer caso, fazer a escarificação na época de semeadura, pois haverá menor ocorrência de sementes mortas. Verificou-se ainda que a diferença de coloração nos lotes de sementes nâo influiu na ocorrência de sementes duras, mas esteve relacionada com a existência de sementes mortas.

\section{INTRODUÇÃO}

As leguminosas forrageiras vêm sendo utilizadas em diversas regiões pecuárias do Brasil, tanto plantadas exclusivamente como consorciadas com gramíneas, visando à maior produção de forragem e aumento no teor

(1) Trabalho a ser apresentado no $1 .{ }^{\circ}$ Congresso Brasileiro de Sementes - Curitiba (PR), de 26 de novembro a 2 de dezembro de 1979. Recebido para publicação em 15 de janeiro de 1979

(“) Com bolsa de suplementação do CNPq. 
protéico. Com o incremento da pecuária, verificou-se uma corrida para aquisição de sementes para plantio. Entretanto, além da escassez de sementes, poucos são os estudos realizados com leguminosas forrageiras, o que tem limitado a obtenção de informações adequadas a respeito dessas leguminosas. No tocante à dureza de sementes, diversos autores têm salientado essa característica em espécies de leguminosas, tais como BURKART (2), ROBINSON (12), PIPER (11), SERPA \& ACHICAR (13), MURO \& AGREDA (7), NEME (8) e LOVADINI \& MIYASAKA (6). Os mesmos autores recomendam que as sementes de tais espécies devam sofrer um processo que permita provocar a permeabilidade do tegumento para melhor germinação. De acordo com a FAO (3), experimento levado a efeito em Uganda mostrou que sementes de calopogônio, cudzu, centrosema e soja-perene apresentaram menos de $25 \%$ de germinação quando não escarificadas. Quanto ao siratro, LOVADINI (5) acha desnecessária a escarificação, uma vez que a ocorrência de sementes duras é de 20\% aproximadamente. Entretanto, HUTTON (4) afirma que o siratro apresenta de 40 a $80 \%$ de sementes duras, dependendo da idade delas e do método de colheita. Com respeito ao cudzu-tropical, TELFORD \& CHILDERS (14) afirmam que suas sementes têm tegumento duro, necessitando de alguma espécie de escarificação.

O objetivo do presente trabalho foi verificar o efeito de diversos métodos de escarificação sobre a germinação de soja-perene, siıatro, centrosema, calopogônio e cudzu-tropical, bem como a longevidade das semen- tes não escarificadas. Estudou-se também a existência de relação entre coloração e ocorrência de sementes duras.

\section{MATERIAL E MÉTODOS}

Foram utilizadas sementes de soja-perene (Glycine wightii), siratro (Macroptilium atropurpureum), centrosema (Centrosema pubescens), calopogônio (Calopogonio mucunoides) e cudzu-tropical (Pueraria phaseoloides), colbidas nos campos de multiplicação da Seção de Leguminosas do Instituto Agronômico. Apćs o beneficiamento manual, o lote de cada espécie foi dividido em dois sublotes: um deles foi armazenado sem escarificação, para que na época de cada semeadura fosse escarificado pelos métodos expostos a seguir; o outro sofreu imediatamente escarificação pelos diversos métodos, com exceção da água quente, sendo assim armazenado. Os diversos sublotes, escarificados ou não, foram armazenados em ambiente normal de laboratório, sem controle de temperatura e umidade relativa. Os testes para determinação de umidade e germinação foram efetuados de acordo com as Regras para Análise de Sementes (BRASIL, 1), de doze em doze meses, durante 36 meses.

Os métodos de escarificação utilizados foram:

a) Escarificação com ácido sulfúrico concentrado - consistiu em colocar as sementes no ácido por vinte minutos, despejar a solução em uma peneira para lavagem em água corrente e, logo após, deixá-las embebidas em água por 60 minutos; 
b) Escarificação por ação do calor a seco - consistiu em submeter as sementes a uma temperatura constante de $65^{\circ} \mathrm{C}$ durante quatro horas;

c) Escarificação com lixa consistiu em atritar as sementes entre lixas de carbureto de silício n. ${ }^{\circ} 36$ durante dois minutos;

d) Escarificação com água quente - consistiu em colocar as sementes em água aquecida à temperatura de $75^{\circ} \mathrm{C}$, durante dez minutos. Este método foi utilizado somente para escarificação periódica.

Com a finalidade de verificar a existência de relação entre coloração e ocorrência de sementes duras, retj raram-se, do lote inicial de cada espécie, vinte amostras de 10 gramas cada uma, para se estabelecer a porcentagem de ocorrência de sementes de tonalidades clara e escura. Após a separação, sementes das duas tonalidades foram postas a germinar. Os testes de germinação, para esse caso, foram realizados no início e aos doze meses de armazenamento.

\section{RESULTADOS E DISCUSSÃO}

3.1. Teor de umidade das sementes

Observaram-se pequenas variações nos teores de umidade das sementes das cinco espécies, durante o período de armazenamento. Conforme se pode notar nos dados inseridos no quadro 1, a centrosema apresentou sementes com maior teor de umidade que as demais espécies tanto no início como no final do armazenamento, quando chegou a atingir $12,6 \%$. Apresentou, também, no final do teste, maior porcentagem de sementes mortas. Para as demais espécies, os teores de umidade das sementes estavam satisfatórios ainda aos 36 meses de armazenamento.

QUADRO 1. - Variações nos teores de umidade nas sementes das cinco espécies, durante o armazenamento

Meses de armazenamento

Espécies

12

24

36

\begin{tabular}{lrrrr}
\hline & $\%$ & $\%$ & $\%$ & $\%$ \\
Soja-perene & 7,7 & 8,0 & 8,5 & 8,9 \\
Siratro & 10,6 & 10,6 & 9,6 & 10,2 \\
Centrosema & 11,9 & 12,5 & 12,2 & 12,6 \\
Calopogônio & 9,3 & 9,3 & 9,0 & 9,5 \\
Cudzu-tropical & 9,8 & 10,0 & 10,0 & 10,1 \\
\hline
\end{tabular}


3.2. Germinação das sementes armazenadas sem escarificação (testemunha)

Os testes de germinação para sementes não escarificadas foram efetuados durante o armazenamento para verificar a variação da porcentagem de germinação apenas pelo repouso das sementes. Esses testes serviram ainda para verificar a ocorrência de sementes duras nos diversos lotes. Pelos dados do quadro 2, verifica-se que a germinação inicial de sementes não escarificadas foi muito baixa para todas as espécies, sendo o maior índice encontrado para centrosema, de $26 \%$. A ocorrência de sementes duras, no início, variou de 65 a $82 \%$. Nas demais épocas de análise houve aumento na porcentagem de germinação para todas as espécies, mais notadamente até os 24 meses. Esse fato demonstra que o simples repouso das sementes, principalmente no caso da centrosema, pode influir favoravelmente na diminuição da ocorrência de sementes duras, pois o período de 24 meses foi suficiente para provocar um aumento de $40 \%$ na porcentagem de germinação das sementes dessa leguminosa, que nessa época apresentava apenas $21 \%$ de sementes duras, ocorrendo, portanto, uma quebra de dormência sem utilização de métodos especiais. Também calopogônio e cudzu-tropical, nos últimos meses de armazenamento, mostravam tendência para aumento na germinação e diminuição na porcentagem de sementes duras, o que não se verificou para siratro e soja-perene. A quebra de dormência foi, portanto, bem nítida em centrosema, já aos doze meses de armazenamento, enquanto em calopogônio e cudzu-tropical foi mais lenta.

QUADRO 2. - Porcentagem de plântulas normais e sementes duras durante o arma zenamento, sem escarificação (testemunha)

\begin{tabular}{|c|c|c|c|c|c|}
\hline \multirow{2}{*}{ Espécies } & & \multicolumn{4}{|c|}{ Meses de armazenamento } \\
\hline & & 0 & 12 & 24 & 36 \\
\hline & & $\%$ & $\%$ & $\%$ & $\%$ \\
\hline Soja-perene & $\begin{array}{l}\text { Normais } \\
\text { Duras }\end{array}$ & $\begin{array}{l}17 \\
69\end{array}$ & $\begin{array}{l}21 \\
62\end{array}$ & $\begin{array}{l}19 \\
63\end{array}$ & $\begin{array}{l}11 \\
73\end{array}$ \\
\hline Siratro & $\begin{array}{l}\text { Normais } \\
\text { Duras }\end{array}$ & $\begin{array}{l}17 \\
82\end{array}$ & $\begin{array}{l}21 \\
73\end{array}$ & $\begin{array}{l}26 \\
66\end{array}$ & $\begin{array}{l}15 \\
68\end{array}$ \\
\hline Centrosema & $\begin{array}{l}\text { Normais } \\
\text { Duras }\end{array}$ & $\begin{array}{l}26 \\
68\end{array}$ & $\begin{array}{l}46 \\
44\end{array}$ & $\begin{array}{l}66 \\
21\end{array}$ & $\begin{array}{l}50 \\
26\end{array}$ \\
\hline Calopogônio & $\begin{array}{l}\text { Normais } \\
\text { Duras }\end{array}$ & $\begin{array}{l}15 \\
78\end{array}$ & $\begin{array}{l}26 \\
64\end{array}$ & $\begin{array}{l}30 \\
61\end{array}$ & $\begin{array}{l}43 \\
43\end{array}$ \\
\hline Cudzu-tropical & $\begin{array}{l}\text { Normais } \\
\text { Duras }\end{array}$ & $\begin{array}{l}22 \\
65\end{array}$ & $\begin{array}{l}26 \\
66\end{array}$ & $\begin{array}{l}39 \\
52\end{array}$ & $\begin{array}{l}38 \\
46\end{array}$ \\
\hline
\end{tabular}


Os dados aqui obtidos para a soja-perene concordam plenamente com os de NEME (8), que concluiu que tais sementes não apresentam o tipo de dormência que possa ser eliminado pelo repouso. Do mesmo modo, pode-se verificar que as sementes de siratro mostraram um comportamento semelhante ao da sojaperene, pois, aos 36 meses apresentaram $15 \%$ de germinação e $68 \%$ de sementes duras. Esses dados concordam com HUTTON (4), que revelou ser o siratro uma espécie que apresenta usualmente 40 a $80 \%$ de sementes duras, dependendo da idade e do método de colheita.

\subsection{Germinação das sementes} submetidas aos diversos métodos de escarificação

\subsubsection{Germinação das sementes} escarificadas com ácido sulfúrico imediatamente após a colheita

Os dados do quadro 3 mostram que a escarificação com ácido sulfúrico imediatamente após a colheita foi bastante eficiente, com índices de germinação acima de $80 \%$ para todas as espécies, sendo praticamente nula a ocorrência de sementes duras. Verificou-se uma queda na porcentagem de germinação já a partir de doze meses, a qual se foi acentuando à medida que se prolongou o armazenamento. Essa queda de germinação se deveu à ocorrência de sementes mortas em alta porcentagem, mostrando a ação prejudicial do ácido sulfúrico durante o armazenamento por períodos longos. Aos 24 meses, a germinação ainda era considerada boa para todas as espécies, menos para a soja-perene, cujo índice de germinação estava abaixo de $50 \%$. Já aos 36 meses, somente o cudzu- tropical apresentou germinação satisfatória, $68 \%$. A soja-perene e a centrosema foram as espécies que mais sentiram a ação do ácido sulfúrico no armazenamento.

\subsubsection{Germinação das sementes escarificadas periodicamente com ácido sulfúrico}

Ainda no quadro 3, acham-se os dados obtidos com a escarificação periódica por ácido sulfúrico. Pode-se notar que esse método foi bastante eficiente para as cinco espécies, em todas as épocas de análises, embora com o tempo de armazenamento ocorressem quedas no poder germinativo, principalmente no caso da soja-perene. A ação escarificadora do ácido sulfúrico aqui verificada concorda com os dados anteriormente obtidos para cudzu-tropical, por MURO \& AGREDA (7) e para siratro, por PHIPPS (10).

Comparando os dados das duas partes do quadro 3 , pode-se verificar que, até os doze meses de armazenamento, praticamente não houve diferença sensível no poder germinativo entre sementes armazenadas já escarificadas, e escarificadas periodicamente. Entretanto, após esse período, a queda no poder germinativo foi mais lenta quando a escarificação foi feita periodicamente. Isso demonstra que para períodos longos de armazenamento é preferível executar a escarificação com ácido sulfúrico no momento da semeadura, e não armazenar as sementes já escarificadas.

3.3.3. Germinação das sementes escarificadas por ação do calor a seco, imediatamente após a colheita

Pelos dados do quadro 4 pode-se verificar que a escarificação com 


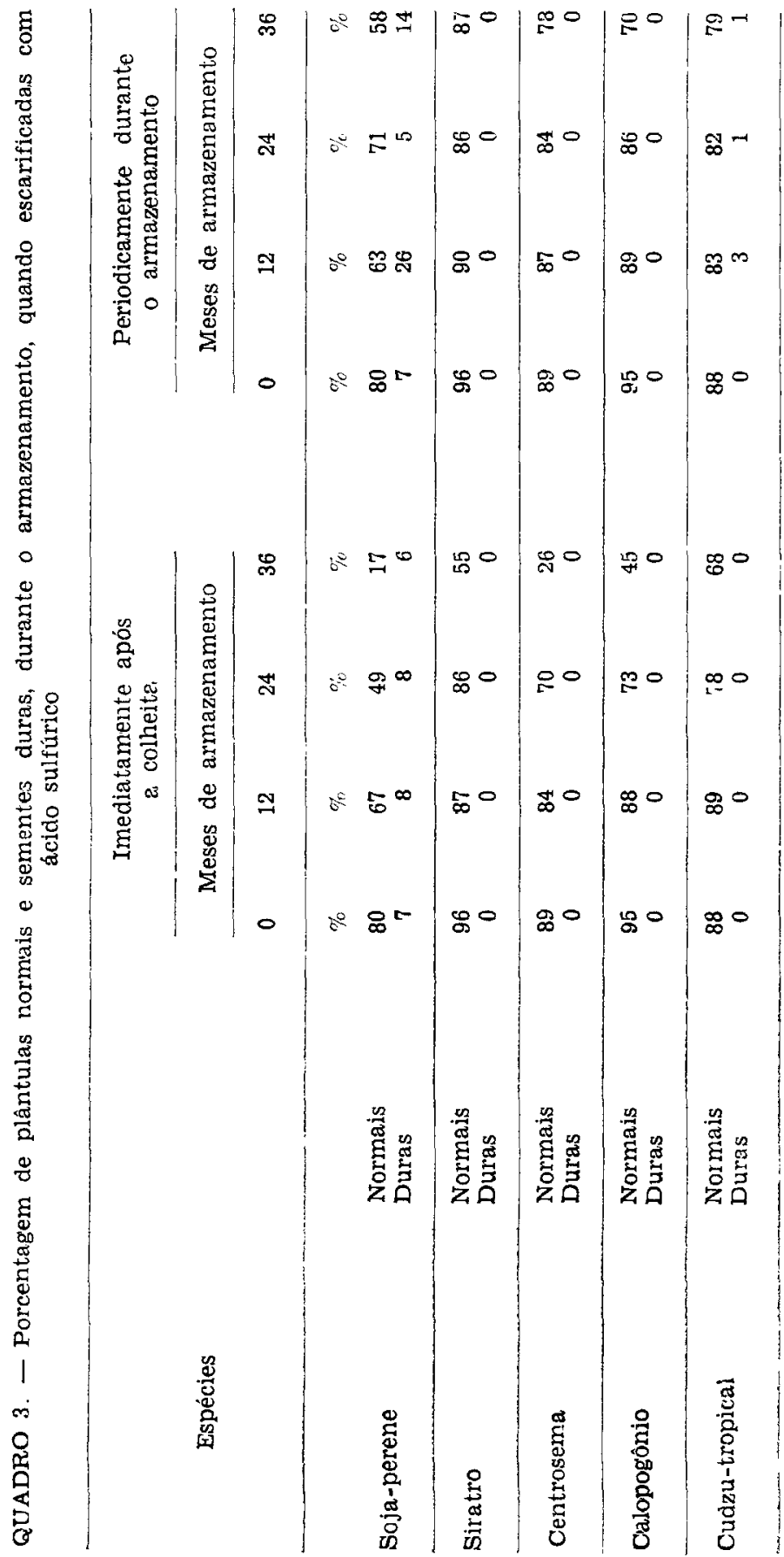


calor, quando executada imediatamente após a colheita não funcionou a contento para a maioria das espécies. Apenas o cudzu-tropical revelou índice ótimo de germinação. A centrosema e o siratro mostraram índices medianos de germinação e de ocorrência de sementes duras. Já o calopogônio e principalmente a sojaperene praticamente não foram afetados pela ação do calor, mostrando índices altos de sementes duras até o final dos testes. Também nesse caso, com o decorrer do período de armazenamento, houve aumento na porcentagem de sementes mortas. Verifica-se, portanto, que a escarificação por ação do calor somente foi benéfica para quebrar a dureza das sementes de cudzu-tropical que, desde o início até os 36 meses, apresentou germinação acima de $77 \%$ e pequena porcentagem de sementes duras. A centrosema e o siratro, apesar de mostrarem porcentagens relativamente baixas de sementes duras, não alcançaram boa germinação devido à morte de sementes no final do teste.

3.3.4. Germinação das sementes escarificadas periodicamente por ação do calor a seco

Também no quadro 4, encontram-se os dados obtidos pela escarificação periódica por ação do calor a seco. Esse tipo de escarificação foi bastante eficiente para o caso do cudzu-tropical, pois, em todas as épocas de análise suas sementes apresentaram índice de germinação acima de $78 \%$. As demais espécies mostraram índices medianos de germinação quando submetidas à escarificação periódica por ação do calor. E interessante notar que durante o ar- mazenamento houve tendência para aumento na porcentagem de germinação e diminuição na ocorrência de sementes duras, conforme já se havia notado na testemunha, sem escarificação.

Comparando as duas partes do quadro 4, verifica-se que para cudzıtropical não houve diferença entre armazenar sementes já escarificadas e proceder à escarificação no momento do plantio, pois a germinação foi ótima para ambos os casos. Para as demais espécies, as sementes escarificadas periodicamente apresentaram melhores condições que aquelas armazenadas já escarificadas, principalmente a soja-perene. Para períodos muito longos de armazenamento, portanto, é preferível proceder-se à escarificação imediatamente antes do plantio, pois haverá melhores índices de Ėerminação.

3.3.5. Germinação das sementes escarificadas por atrito entre lixas, imediatamente após a colheita

$O$ atrito das sementes entre lixas pelo período de dois minutos não resultou na escarificação das sementes de modo satisfatório, pois os índices de ocorrência de sementes duras foram altos, principalmente no início, caindo um pouco até 36 meses de armazenamento, conforme o quadro 5. Entretanto, não se notou melhoria sensível no poder germinativo das sementes das espécies estudadas, devido ao aumento de ocorrência de sementes mortas, consequiência do longo tempo de armazenamento. A sojaperene foi a espécie menos afetada pelo atrito entre as lixas e, a centrosema, aquela que mostrou os melhores resultados. 
Vol. 38, N.o 9

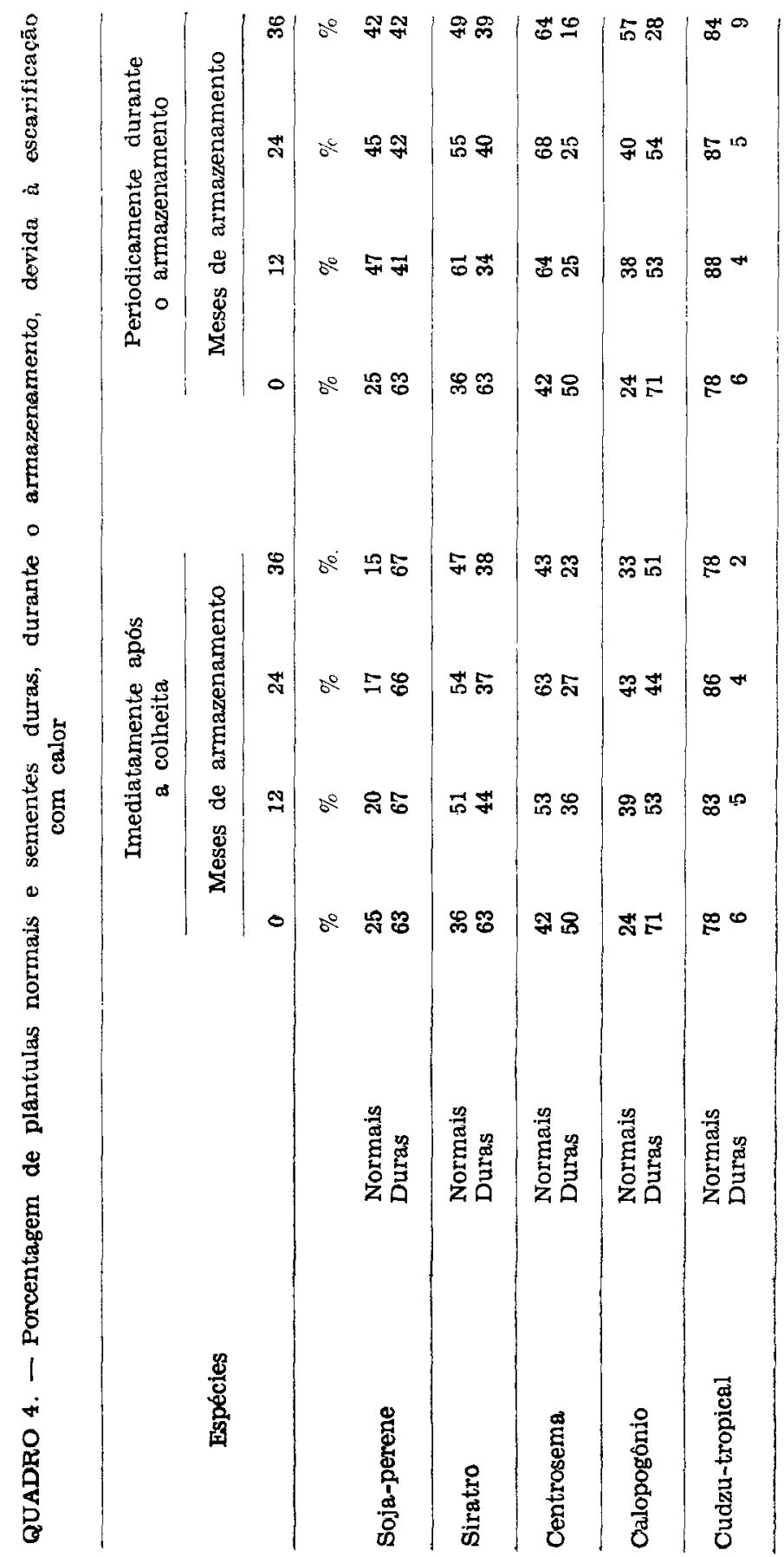


Almeida, MAEDA \& Falivene

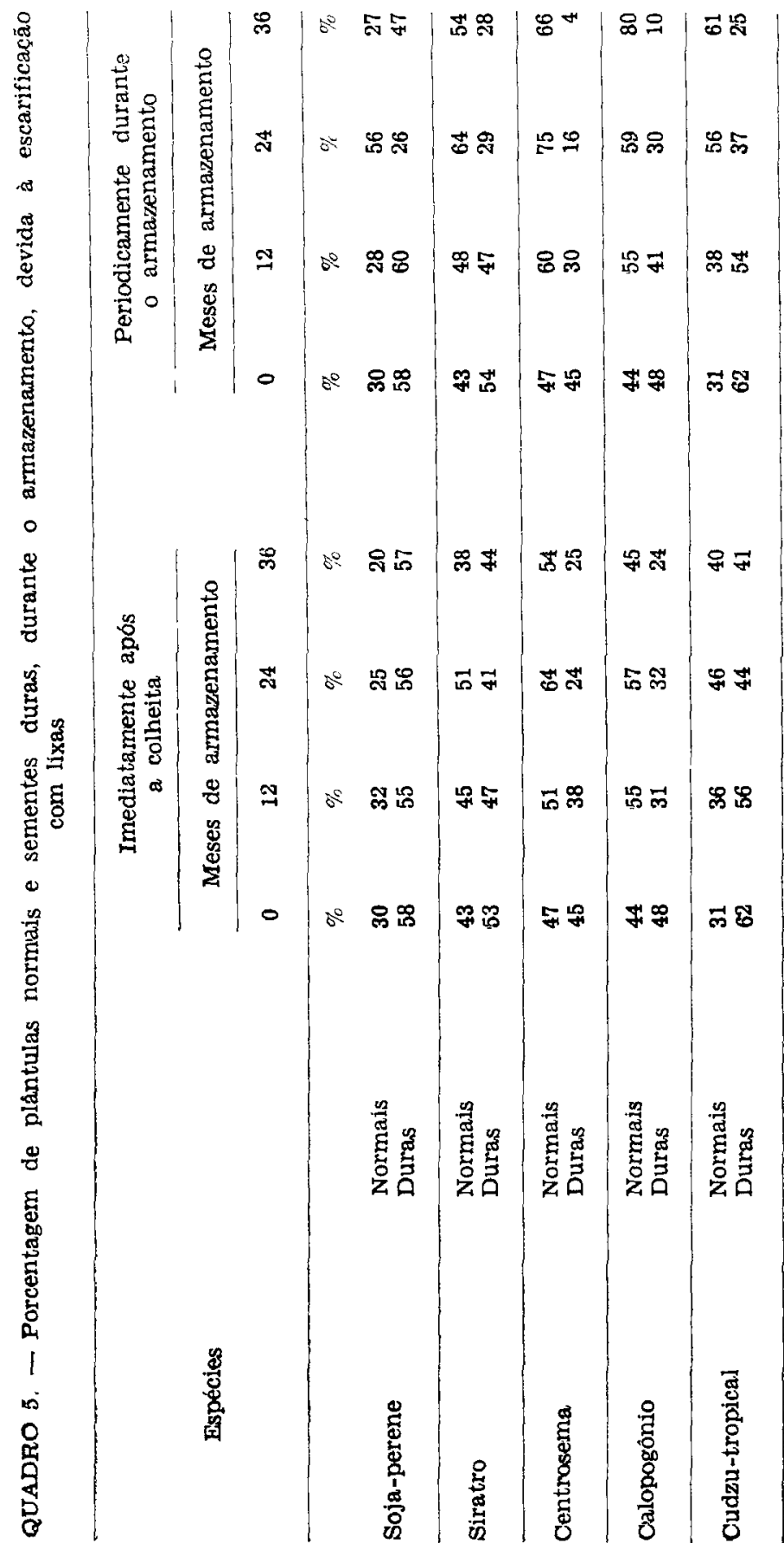


3.3.6. Germinação das sementes escarificadas periodicamente pelo atrito entre lixas

Os dados do quadro 5 mostram que esse método não funcionou realmente de modo satisfátório, principalmente para soja-perene e cudzutropical, pois os índices de ocorrência de sementes duras podem ser considerados altos, principalmente nas épocas iniciais. Para siratro, centrosema e calopogônio, verificaram-se bons índices de germinação, a partir de doze meses de armazenamento. A explicação para as variações ocorridas é que, embora se tenha utilizado o tempo constante de dois minutos para escarificação, houve certa influência do operador, que não foi o mesmo em todas as épocas. $O$ método de escarificação com lixas poderá funcionar a contento desde que se aumente o tempo de escarificação, dependendo ainda do operador. Entretanto, cuidados deverão ser tomados para que não haja grande porcentagem de sementes quebradas e danificadas internamente. Acreditamos, ainda, que para quantidades grandes de sementes, de qualquer das espécies estudadas, poderá ser empregada com vantagem a máquina denominada "escarificador IAC", conforme preconizado por NEME (9), que a utilizou com bons resultados para a sojaperene.

Pelos dados do quadro 5 podemos verificar que a escarificação periódica ofereceu melhores resultados de germinação, com menor porcentagem de ocorrência de sementes duras, quando comparada com a escarificação efetuada logo após a colheita.

De modo geral, e para as condições desta experiência, a escarifica- ção de sementes entre lixas funcionou razoave'mente para algumas das espécies estudadas, embora tenha provocado melhores índices de germinação em relação à testemunha, não escarificada.

3.3.7. Germinação das sementes escarificadas periodicamente com água quente

Os dados do quadro 6 mostram os resultados obtidos com a escarificação das sementes com água quente, nas diversas épocas de análise. Inicialmente, somente o calopogônio e o siratro mostraram ótimos índices de germinação e baixa porcentagem de sementes duras, enquanto a centrosema e o cudzu-tropical tiveram índices bons de germinação, mas ainda com ocorrência significante de sementes duras. A soja-perene apresentou baixo índice de germinação e alta porcentagem de sementes duras.

Com o decorrer do período de armazenamento, algumas alterações interessantes se verificaram: para calopogônio e centrosema houve diminuição na porcentagem de germinação e na ocorrência de sementes duras. Para soja-perene e cudzu-tropical, praticamente não houve redução no índice de germinação, mas houve grande redução na porcentagem de sementes duras. Em ambos os casos, principalmente nas épocas finais, houve alta porcentagem de sementes mortas. Das cinco espécies, apenas - siratro mostrou ótimo comportamento até o final dos testes. Verifica-se, portanto, que a utilização da água quente é um método que funciona muito bem para quebrar a dureza das sementes; entretanto, provoca, na maioria das espécies, alta 
QUADRO 6. - Porcentagem de plântulas normais e sementes duras, durante o armazenamento, através de escarificaçāo periódica com água quente

Espécies

Meses de armazenamento

\begin{tabular}{llrrrr} 
& & 0 & 12 & 24 & 36 \\
& & $\%$ & $\%$ & $\%$ & $\%$ \\
Soja-perene & Normais & 35 & 55 & 39 & 49 \\
& Duras & 49 & 16 & 16 & 4 \\
\hline \multirow{2}{*}{ Siratro } & Normais & 77 & 82 & 71 & 80 \\
& Duras & 8 & 3 & 4 & 3 \\
\hline \multirow{3}{*}{ Centrasems } & Normais & 59 & 52 & 42 & 38 \\
& Duras & 29 & 7 & 5 & 6 \\
\hline \multirow{3}{*}{ Calopogônio } & Normais & 83 & 69 & 64 & 57 \\
& Duras & 10 & 0 & 5 & 7 \\
\hline \multirow{2}{*}{ Cudzu-tropical } & Normais & 62 & 58 & 66 & 56 \\
& Duras & 30 & 12 & 11 & 9 \\
\hline
\end{tabular}

porcentagem de ocorrência de sementes mortas, principalmente quando o armazenamento é prolongado.

\subsection{Influência da coloração} na ocorrência de sementes duras

Algumas observações anteriores em testes de germinação de sementes de leguminosas forrageiras deram idéia de que a coloração da semente, que em algumas espécies é bastante variável, pudesse estar relacionada com a ocorrência de sementes duras. A separação das sementes em tonalidades claras e escuras ofereceu os seguintes resultados: a) soja-perene, $95 \%$ escuras e $5 \%$ claras; b) cudzutropical, $95 \%$ claras e $5 \%$ escuras; c) calopogônio, $90 \%$ claras e $10 \%$ escuras; d) centrosema, $85 \%$ claras e $15 \%$ escuras; e) siratro, $60 \%$ claras e $40 \%$ escuras.
Os dados do quadro 7 mostram que a porcentagem de plântulas normais, obtidas para as cinco espécies, é praticamente a mesma tanto para sementes claras como para escuras, havendo variações de pequena relevância. Examinando as porcentagens de sementes duras, obtidas nos dois testes, verifica-se realmente que, para calopogônio e cudzu-tropical, as sementes de tonalidade clara mostraram uma porcentagem maior de sementes duras que aquelas de tonalidade escura. Supondo que os testes tivessem sido instalados somente para verificar a presença de sementes duras, estaria caracterizada a influência da coloração, clara no caso, na ocorrência de maior porcentagem de sementes duras. Entretanto, num exame mais apurado, pode-se notar que para as duas espécies ocorre uma porcentagem significativa de sementes mor- 


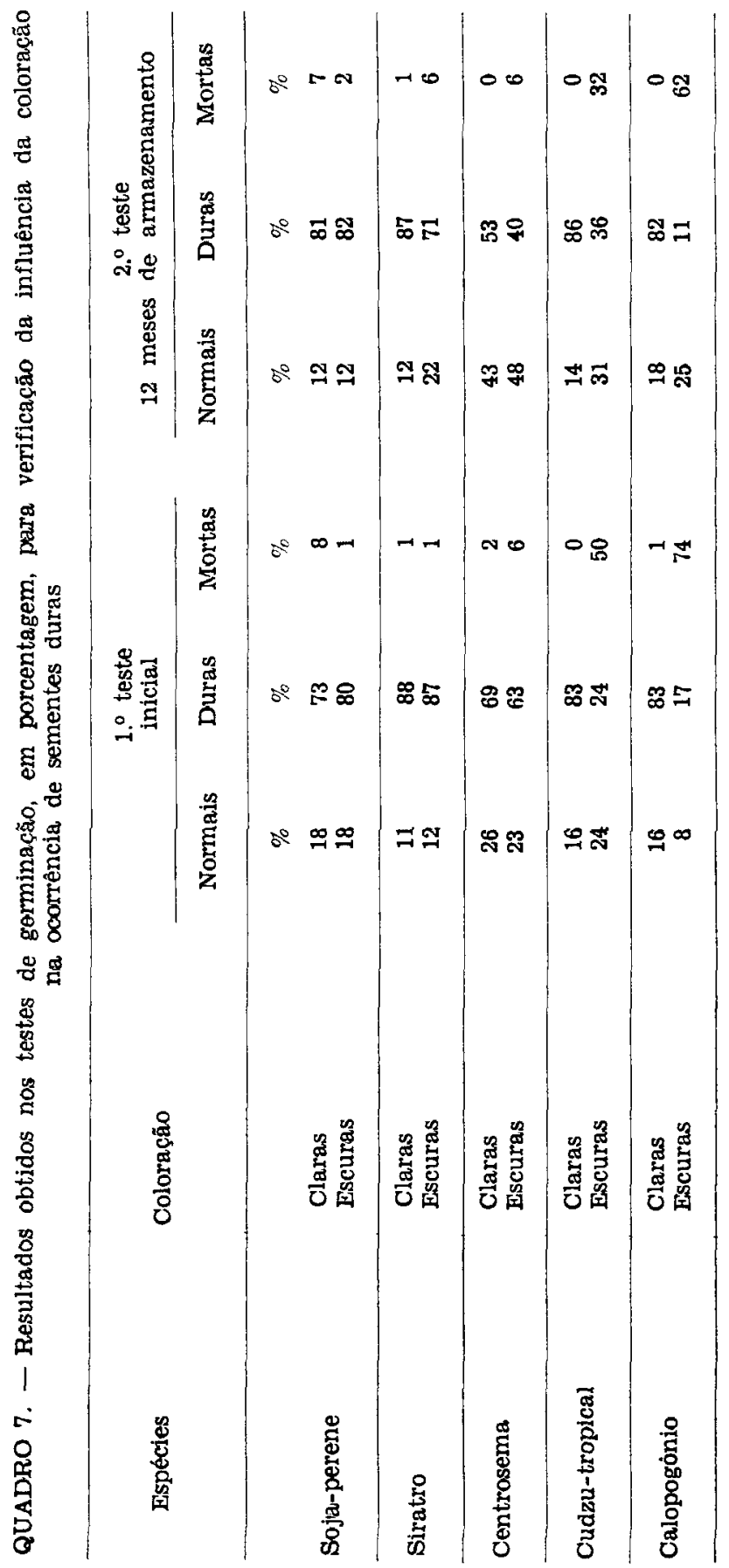


tas, quando se trata de sementes de coloração escura. Ora, levando em consideração que os lotes de sementes tanto de calopogônio como de cudzu-tropical eram constituídos de mais de $85 \%$ de sementes claras, fica evidente que esta coloração é normal e constituída de sementes perfeitamente maduras e viáveis. Por outro lado, as quantidades de sementes escuras encontradas constituem a minoria e representam, provavelmente, sementes fisiologicamente imaturas e, portanto, com maiores possibilidades de se apresentarem mortas. Dessa maneira, fica evidente que a influência da coloração não está relacionada com a ocorrência de sementes duras, mas sim com a porcentagem de sementes mortas, por uma questão de maturação.

No caso de soja-perene, siratro e centrosema, foi verificado que as porcentagens de plântulas normais $\mathbf{e}$ de sementes duras e mortas eram bastante semelhantes, tanto para sementes claras como para escuras. Neste caso, trata-se provavelmente de mistura de cultivares, com variação na coloração de sementes. Para essas três espécies, é viável um trabalho de melhoramento, visando à seleção de cultivares com coloração uniforme de sementes.

Para o caso das demais leguminosas em estudo, haveria necessidade de se proceder a uma separação das sementes, visando eliminar as escuras, que, como visto, seriam de baixa viabilidade.

\section{CONCLUSÕES}

a) $\mathrm{O}$ poder germinativo das espécies estudadas foi bastante baixo, em se tratando de sementes sem esca- rificação, com ocorrência de alta porcentagem de sementes duras.

b) Para centrosema, o fenômeno de ocorrência de sementes duras pode ser eliminado pelo repouso das sementes, mais rapidamente que para as demais espécies.

c) Para boa germinação, as sementes das cinco espécies precisam sofrer um processo de escarificação, que deve ser efetuado, de preferência, imediatamente antes do plantio.

d) A escarificação com ácido sulfúrico concentrado aumentou a porcentagem de germinação das sementes de todas as espécies, chegando a atingir níveis bem elevados.

e) Entre os demais métodos, o do calor foi ótimo para cudzu-tropical, o da água quente proporcionou bons índices de germinação para siratro e calopogônio, e o do atrito entre lixas, apesar de mostrar algum efeito de escarificação, foi o menos eficiente.

f) $\mathrm{O}$ armazenamento, por longo período, de sementes já escarificadas, principalmente com ácido sulfúrico, aumenta a porcentagem de ocorrência de sementes mortas.

g) Para qualquer dos métodos de escarificação estudados, é sempre preferivel proceder à escarificação na época da semeadura.

h) A soja-perene revelou ser a espécie cujas sementes foram menos sensíveis a qualquer dos métodos de escarificação utilizados.

i) A coloração escura das sementes não esteve relacionada com a ocorrência de sementes duras, mas, em certas espécies, mostrou forte relação com o aparecimento de sementes mortas. 


\section{SCARIFICATION OF SEEDS OF FORAGE LEGUMES}

\section{SUMMARY}

Five species of forage legumes, Glycine (Glycine wightii), Siratro (Macroptilium atropurpureum), Centro (Centrosema pubescens), Calopo (Calopogonio mucunoides), and Tropical Kudzu (Pueraria phaseoloides), were studied as to the germination of the seeds considering the need of scarification, just after harvesting and during the storage period. Four scarification methods were evaluated, i.e., by concentrated sulfuric acid, heat, scratching between sandpapers, and hot water. Relation between seed coat coloration and occurrence of hard seeds was also studied.

When non scarified, the five species presented high percentages of hard seeds and, with the exception of Centro, aging during normal storage conditions did not enhance the germination of the seeds.

The germination was increased by all scarification methods, the sulfuric acid being very efficient, for all species. The heat treatment was better for Tropical Kudzu and scratching between sandpapers was just moderate for all species. Hot water treatment provided good germination percentages for Siratro and Calopo, but caused occurrence of high percentages of dead seeds at the final of the storage period. In long storage periods it is preferable, in any case, to make the scarification just before planting, because the occurrence of dead seed will be lower. Finally, it was observed that the difference of coloration in the seed lots did not influence the occurrence of hard seeds but was related to the existence of dead seeds.

\section{LITERATURA CITADA}

1. BRASIL, Ministério da Agricultura. Divisão Técnica de Sementes e Mudas. Regras para análise de sementes. Brasília, 1976 . $188 \mathrm{p}$.

2. BURKART, A. Las leguminosas argentinas, silvestres y cultivadas. 2. ed. Buenos Aires, Acme Agency, 1952 . 569p.

3. FAO. Las semillas agrícolas y hortícolas. Roma, 1961. 616 p. (Estudios agropecuarios. 55)

4. HUTTON, E. M. Siratro - a tropical pasture legume bred from Phaseolus atropurpureus. Aust. J. exp. Agric. Anim. Husb., 2:117-125, 1962.

5. LOVADINI, L. A. C. Algumas informaçōes sobre o siratro. Campinas, Instituto Agronômico, 1970. 3p. (Mimeografado)

6. ——_ \&IYSAKA, S. Cultura da soja-perene. Campinas, Instituto Agronômico, 1968. 28p. (Boletim, 186)

7. MURO, J. del C. \& AGREDA, O. Kudzu tropical en la selva peruana. Lima, Peru, Minist. Agric., Servicio de Investigación y Promoción Agraria, 1962. 15p. (Boletin técnico, 33)

8. NEME, N. A. Sementes de soja-perene. Resultados da escarificação e duração do poder germinativo. Bragantia, Campinas, 22:785-791, 1963.

9. - Escarificador "IAC" para seinentes de soja-perene. Bragantia, Campinas, 25-XIX-XXI, 1966. (Nota 5)

10. PHIPPS, R. H. Methods of increasing the germination percentage of some tropical legumes. Trop. Agric., Trinidad, 50(4) :291-296, 1973.

11. PIPER, C. V. Forage plants and their culture. New York, MacMillan, 1927. 671p.

12. ROBINSON, D. H. Leguminous forage plants. 2. ed. London, Edward Arnold, 1953. 119p.

13. SERPA, A. \& ACHICAR, J. Influência do periodo de maturação na produção de sementes duras em Centrosema pubescens. Pesq. agropec. bras.. Brasilia. 5:125-128, 1970.

14. TELFORD, E. A. \& CHILDERS, M. F. Tropical kudzu in Puerto Rico. Mayaguez, Puerto Rico, Federal Experiment Station, 1947. 30p. (Circular, 27) 